\title{
Time-varying Optimal Hedge Ratio for Brent Oil Market
}

\author{
Mohsen Mehrara, Monire Hamldar \\ Faculty of Economics, University of Tehran, Tehran, Iran \\ E-mail address: mmehrara@ut.ac.ir \\ hamldar@ut.ac.ir
}

Keywords: OHR, Multivariate GARCH models, BEKK, efficiency

\begin{abstract}
This paper examines the optimal hedging ratio (OHR) for the Brent Crude Oil Futures using daily data over the period 1990/17/8-2014/11/3. To estimate OHR, we employ multivariate BEKK MV-GARCH model. At last, the efficiency of this approach are compared with the constant OHR captured from OLS through Edrington's index.
\end{abstract}

\section{INTRODUCTION}

Price risk management, using hedging tools like futures and options and their effectiveness, is an active area of research. Hedging decisions based on futures contracts have to deal with finding optimal hedge ratio and hedging effectiveness. Role of hedging using multiple risky assets and using futures market for minimizing the risk of spot market fluctuation has been extensively researched.

The traditional approaches to the use of futures for hedging purposes has been to either adopt a naive one-to-one hedging ratio to determine the optimal hedge ratio using simple regression techniques, but to assumet hat this ratio will remain constant over the relevant time horizon. However, empirical financial markets research over the past two decades has supported the view that asset returns volatility is time-varying and, in particular, exhibits 'clustering', such that large (small) returns follow large (small)returns of random sign (Mandelbrot, 1963; Fama, 1965) and whereby the standard way of specifying volatility is through the generalized autoregressive conditional heteroscedasticity (GARCH) model (Engle, 1982; Bollerslev, 1986).1 Moreover, accurate estimation of the volatility process plays an essential role in many aspects of financial markets, for example,variation in market returns and other economy-wide riskfactors are a main feature of asset and portfolio managementand play a key role in derivatives pricing models. As suchaccurate measures and forecasts of volatility are crucial for theimplementation and evaluation of asset and derivative pricingmodels in addition to trading and hedging strategies. Therefore,knowledge of the volatility process should allow market agentsto improve their estimates of optimal cash-futures hedge ratiosover the implementation of strategies based upon constanthedging ratios.2 Moreover, Park and Switzer (1995) argue thatif the joint distribution of cash and futures prices is changingover time then a constant hedge ratio may not be appropriate, while Baillie and Myers (1991) likewise suggest that hedgeratios will vary over time as the conditional distributionbetween cash and futures price changes.

\section{METHODOLOGY AND EMPIRICAL RESULTS}

In this section we use the GARCH models to calculatethe optimal hedging ratio for Brent Oil Market. The financial variables used in the model are spot and futures price of Brent Oil.The data series are obtained from Energy Information Agency(EIA). The data are daily from 1990/17/82014/11/3.

\section{OLS Method}

In this method changes in spot price is regressed on the changes in futures price. The MinimumVariance Hedge Ratio has been suggested as slope coefficient of the OLS regression. It is the ratio of 
covariance of (spot prices, futures prices) and variance of (futures prices). The R-square of this model indicates the hedging effectiveness. The OLS equation is given as:

$$
R_{s t}=\alpha+H \cdot R_{f t}+\varepsilon_{t}
$$

Where, $\mathrm{R}_{\mathrm{St}}$ and $\mathrm{R}_{\mathrm{Ft}}$ are $\log$ of spot and futures return, $\mathrm{H}$ is the optimal hedge ratio and $\varepsilon_{\mathrm{t}}$ is the error term in the OLS equation. Many empirical studies use the OLS method to estimate optimal hedge ratio, however this method does not take account of conditioning information (Myers \& Thompson, 1989) and ignores the time varying nature of hedge ratios (Cecchetti, Cumby, \&Figlewski, 1988). It also does not consider the futures returns as endogenous variable and ignores the covariance between error of spot and futures returns. The advantage of this model is the ease of implementation.

\section{THE VAR-MGARCH MODEL}

Generally, time series data of return possesses time varying heteroscedastic volatility structure or ARCH-effect (Bollerslevet al, 1992). Due to ARCH effect in the returns of spot and futures prices and their time varying joint distribution, the estimation of hedge ratio and hedging effectiveness may turn out to be inappropriate. Cecchetti, Cumby, and Figlewski (1988) used ARCH model to represent time variation in the conditional covariance matrix of Treasury bond returns and bond futures to estimate time-varying optimal hedge ratios and found substantial variation in optimal hedge ratio. The VAR-MGARCH model considers the ARCH effect of the time series and calculate time varying hedge ratio. A bivariate $\operatorname{GARCH}(1,1)$ model is given by:

$R_{s t}=\alpha_{s}+\sum_{i=1}^{k} \beta_{s i} R_{s t-i}+\sum_{j=1}^{l} \gamma_{f j} R_{f t-i}+\varepsilon_{s t}$
$R_{s t}=\alpha_{s}+\sum_{i=1}^{k} \beta_{s i} R_{s t-i}+\sum_{j=1}^{l} \gamma_{f j} R_{f t-i}+\varepsilon_{s t}$

$\left[\begin{array}{l}h_{s s} \\ h_{s f} \\ h_{f f}\end{array}\right]=\left[\begin{array}{l}C_{s s} \\ C_{s f} \\ C_{f f}\end{array}\right]+\left[\begin{array}{lll}\alpha_{11} & \alpha_{12} & \alpha_{13} \\ \alpha_{21} & \alpha_{22} & \alpha_{23} \\ \alpha_{31} & \alpha_{32} & \alpha_{33}\end{array}\right]\left[\begin{array}{c}\varepsilon_{s}^{2} \\ \varepsilon_{s} \varepsilon_{f} \\ \varepsilon_{s}{ }^{2}\end{array}\right]_{t-1}+\left[\begin{array}{lll}\beta_{11} & \beta_{12} & \beta_{13} \\ \beta_{21} & \beta_{22} & \beta_{23} \\ \beta_{31} & \beta_{32} & \beta_{33}\end{array}\right]\left[\begin{array}{l}h_{s s} \\ h_{s f} \\ h_{f f}\end{array}\right]_{t-1}$

where, $\mathrm{h}_{\mathrm{ss}}$ and $\mathrm{h}_{\mathrm{ff}}$ are the conditional variance of the errors $\varepsilon_{\mathrm{st}}$ and $\varepsilon_{\mathrm{ft}}$ and $\mathrm{h}_{\mathrm{sf}}$ is the covariance.

Bollerslevet al. (1988) proposed a restricted version of the above model in which the only diagonal elements of $\boldsymbol{\alpha}$ and $\boldsymbol{\beta}$ matrix are considered and the correlations between conditional variances are assumed to be constant. The diagonal representation of the conditional variances elements $h_{\mathrm{ss}}$ and $\mathrm{h}_{\mathrm{ff}}$ and the covariance element $\mathrm{h}$ is presented as (Bollerslevet al., 1988):

Time varying hedge ratio is calculated as follows:

$$
H_{t}=\frac{h_{s f}}{h_{f f}}
$$

\section{HEDGE RATIO AND HEDGING EFFECTIVENESS}

Hedging effectiveness is defined as the ratio of the variance of the unhedged position minus variance of hedge position over the variance of unhedged position.

$$
\begin{gathered}
\text { Hedging Effectiveness }(\mathrm{E})=1-\frac{\operatorname{Var}(H)}{\operatorname{Var}(U)} \\
\qquad \begin{array}{c}
\boldsymbol{V a r}(\boldsymbol{H})=\boldsymbol{\sigma}_{s}{ }^{\mathbf{2}}+\boldsymbol{H}^{\mathbf{2}} \boldsymbol{\sigma}_{\boldsymbol{f}}{ }^{\mathbf{2}}-\mathbf{2} \boldsymbol{H} \boldsymbol{\sigma}_{s, \boldsymbol{f}} \\
\boldsymbol{V a r}(\boldsymbol{U})=\boldsymbol{\sigma}_{s}{ }^{\mathbf{2}}
\end{array}
\end{gathered}
$$




\section{THE RESULTS OF ESTIMATES}

OLS regression (equation [1]) has been used to calculate the hedge ratio and hedging effectiveness. The slope of the regression equation gives the hedge ratio and $\mathrm{R}^{2}$, the hedging effectiveness.

$$
\begin{gathered}
d(\text { lspot })=0.715 d(\text { lfuture })+\varepsilon_{t} \\
\mathrm{R}^{2}=0.48 \\
\operatorname{Var}(\boldsymbol{H})=0.53+(\mathbf{0 . 7 1 5})^{2} \cdot(\mathbf{0 . 5 2})-2 .(0.715) .(0.52)=0.052237 \\
\operatorname{Var}(\boldsymbol{U})=0.53 \\
E=1-\frac{0.052237}{0.53}=0.9
\end{gathered}
$$

VAR-MGARCH model is used to modify the estimation of hedge ratio for time varying volatility and to incorporate non-linearity in the mean equation. Errors of the VAR and VECM models are analyzed for presence of "ARCH effect" and it was found that the errors have time varying volatility.

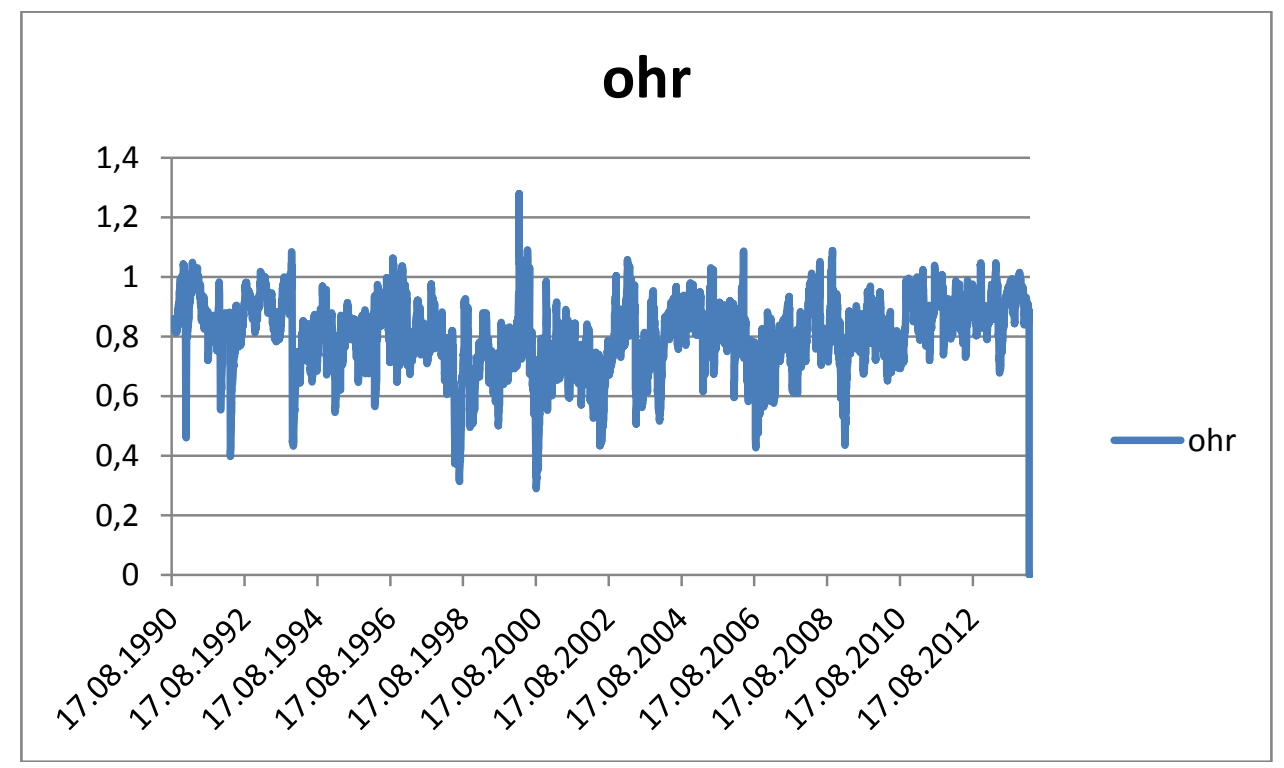

Table 1: Statistical properties of dynamic hedge ratio fromVAR-MGARCH model

\begin{tabular}{|c|c|c|c|c|}
\hline $\begin{array}{c}\text { Brent crude } \\
\text { oil market }\end{array}$ & Min & Max & Mean & SD \\
\hline Future 1 & 0.29 & 1.27 & 0.8 & 0.11 \\
\hline
\end{tabular}

\section{CONCLUSION}

We calculate the optimal hedge ratio through OLS and VAR-MGARCH. The OHR calculated through OLS is constant over the time but VAR-MGARCH OHR represent time variation in the conditional covariance matrix and according to transaction cost, hedger should manage the risk. According to results of estimates, OHR calculated through BEKK VAR-MGARCH is higher than the OLS and efficiency of BEKK VAR-MGARCH is more than the OLS in Brent Crude oil market. 


\section{References}

[1] McMillan, D. G., 2005."Time-varying hedge ratios for non-ferrous metals prices ".Resources Policy 30 (2005) 186-193

[2] Chen, S. S., Lee, C. F., and Shrestha, K. (2003). Futures hedge ratios: a review. The Quarterly Review of Economics and Finance 43 , 433-465.

[3] Ederington, L. H. (1979). The hedging performance of the new futures markets. Journal of Finance, 34, 157-170.

[4] Litterman, R. B., 1986. "Forecasting With Bayesian Vector Autoregressive -- Five Years of Experience," Journal of Business \& Economic Statistics 4, 25-38.

[5] Sims, C.A. and Tao Zha. 1998. "Bayesian Methods for Dynamic Multivariate Models." International Economic Review. 39(4):949-968.5.

[6] Mehrara, M, and Monire Hamldar,"Optimal Hedge Ratio for Brent Oil Market; BaysianApproach", International Letters of Social and Humanistic Sciences 26 (2014) 82-87. 